\title{
Aspectos não explícitos das representações sociais da beleza física em relacionamentos amorosos
}

\author{
Non-explicit aspects of social representations of physical beauty in romantic \\ relationships
}

\author{
Adriano Schlösser ${ }^{1}$ \\ Brigido Vizeu Camargo ${ }^{2}$
}

\begin{abstract}
RESUMO: A beleza física é considerada um atributo importante nas relações interpessoais e atração interpessoal. Em se tratando de relacionamentos amorosos, pode apresentar conflitos entre as normas socialmente partilhadas e opiniões não expressas. O presente estudo objetivou investigar a existência de uma zona muda das representações sociais da beleza física em contexto de estabelecimento de relacionamentos amorosos. Trata-se de um estudo descritivo e comparativo, de recorte transversal e amostragem intencional. Participaram 120 pessoas, distribuídos de modo equivalente entre homens e mulheres, 60 deles fazendo parte do grupo que atua como modelo fotográfico, e outros 60 com indivíduos que cursam o ensino superior na área de Ciências Exatas ou Tecnológicas. Para a coleta de dados, utilizou-se um questionário online autoadministrado, com respostas abertas e fechadas. Foi composto da seguinte forma: a) descrição de um personagem fictício, contendo informações sobre sua personalidade, aspectos físicos e como se relaciona em relacionamentos amorosos; b) definição do sexo do personagem; c) teste de evocação; d) técnica de substituição e) questões sócio-demográficas. Realizou-se análise estatística descritiva e relacional, com auxílio do SPSS 17.0. Utilizou-se o software Evocation 2005 para realizar a análise do teste de evocação e de substituição. A zona muda da representação social da beleza indicou que os participantes tanto a consideram abertamente como um atributo central no estabelecimento de relações amorosas, quanto percebem que outras pessoas consideram da mesma forma.
\end{abstract}

Palavras-chave: representações sociais; zona muda; relacionamento amoroso; atração interpessoal; beleza física.

ABSTRACT: Physical beauty is considered an important attribute in interpersonal relationships and interpersonal attraction. When it comes to love relationships, may present conflicts between socially shared norms and unexpressed opinions. The present study aimed to investigate the existence of a zone of change social representations of physical beauty in the context of establishing loving relationships. We perform a comparative and descriptive study, bsed on crosssectional data obtained by purposive sampling. Out of 120 participants, 60 are men and 60 are women. Moreover, 60 are professional photo models and 60 attend to higher education on Exact or Technological Sciences. We utilized a self-administered with open and close questions. Was composed as follows : a) description of a fictional character, containing information about your personality, physical aspects and how it relates to romantic relationships; $b$ ) definition of the sex of the character ; c ) evocation test; d ) replacement technique and ) socio- demographic questions. We use a several methods to analysis the data: the descriptive and relational statistics analysis in made thorough the software SPSS 17.0, and the evocation and frequency analysis through Evocation. The mute zone of beauty social representation indicated that the participants professedly consider it of fundamental importance for the establishment of romantic relationships. They also realize that other people consider the physical beauty the same way.

\footnotetext{
${ }^{1}$ Mestre em Psicologia; Doutorando do Programa de Pós-Graduação em Psicologia da Universidade Federal de Santa Catarina; Membro do Laboratório de Psicologia Social da Comunicação e Cognição - Florianópolis, SC, Brasil. E-mail: adriano.psicologia@yahoo.com.br.

2 Doutor em Psicologia; Professor do Programa de Pós-Graduação em Psicologia da Universidade Federal de Santa Catarina e Diretor do Laboratório de Psicologia Social da Comunicação e Cognição - Florianópolis, SC, Brasil.
} 
Keywords: social representations; mute zone; romantic relationship; interpersonal attraction; physical beauty.

\section{Introdução}

O fenômeno da beleza física sempre foi um tema presente na construção do pensamento humano, propiciando teorias, acepções e divagações em torno do belo. Para Sócrates, a especificidade da beleza de um corpo é somente um modelo da beleza dos corpos em geral, sendo que, quando nos damos conta disso, a fixação por um corpo em particular minimiza e passa-se a apreciar a beleza onde quer que ela se encontre, desde a filosofia até a essência do belo na corporeidade das formas.

Como objeto de estudo científico, o estudo sobre relacionamentos, atração interpessoal e beleza é composto por diferentes áreas do conhecimento, como a antropologia, etologia, sociologia e comunicação. No campo da ciência psicológica, a atratividade física é considerada como o grau em que as características físicas de um indivíduo são consideradas esteticamente belas. Dentre os aspectos que influenciam na atração, os aspectos físicos são um deles (Dion, Bersheid \& Walster, 1972). Pode ser estudados por meio de diversas facetas, desde aspectos universais presentes em sociedades distintas até aspectos individuais ou de nível grupal.

O conceito de beleza física adotado nesta pesquisa baseia-se na definição de Andrieu (2006), sendo a beleza uma qualidade atribuída a um corpo por um indivíduo ou uma sociedade, tendo em vista que uma imagem que agrada a um grupo tende a tornar-se um molde, sendo posteriormente reproduzida pelos demais. A percepção da atratividade física também exerce influência na avaliação e julgamento social, repercutindo em diversas práticas sociais, como relações de amizade, relacionamentos amorosos, comportamento sexual e atividade profissional (Biddle \& Hamermesh, 1995; Hamermesh, 2011; Hamermesh \& Biddle, 1993; Hamermesh \& Parker, 2005; Schlösser, 2013; Schlösser \& Camargo, prelo).

Propagandas, programas, revistas e outros meios midiáticos divulgam, de maneira indireta, que a aparência física é responsável pelo sucesso e felicidade nas relações interpessoais. Isso passa a formar a percepção de que, para alcançar tais ganhos, é necessário possuir determinados padrões estéticos, contando assim com a ajuda da indústria da beleza, que veicula soluções rápidas para atingir o padrão estético ideal (Goetz, 2009). Culturalmente, associam-se aos indivíduos considerados belos, entre outras, as seguintes atribuições: popularidade, inteligência, confiança, sensualidade, experiência, maior oportunidade de flertes e de ter amigos (Etcoff, 1999).

Estudos apontam a associação de características socialmente positivas em indivíduos fisicamente atraentes, como inteligência, honestidade, extroversão, felicidade e popularidade. (Cash, Gillen \& Burns, 1977; Dion, Berscheid \& Walster, 1972; Kanazawa, 2011; Schlösser, 2013). O estudo de Kanazawa (2011), por exemplo, identificou maior associação entre atratividade física e inteligência entre o sexo masculino do que entre o sexo feminino. A pesquisa realizada por Hamermesh e Abrevaya (2013) sobre o impacto da aparência física sobre a satisfação com a vida e a felicidade, verificou que pessoas bonitas se consideravam mais felizes do que pessoas menos bonitas, tendo em vista os benefícios provenientes da beleza que poderiam explicar esta felicidade. 
Essa situação pode ser explicada usando por base a teoria do efeito halo, que considera que a avaliação de uma característica interfere no julgamento das demais, contaminando o resultado geral (Rosenzweig, 2007). Também pode desencadear em uma profecia autorrealizadora, em que uma crença tende a afetar os comportamentos, aumentando a probabilidade de ocorrer aquilo em que se acredita ou se teme (Copeland, 1994). Isso pode se verificar em casos onde há uma maior atenção despendida desde a infância a uma criança considerada bela, tendendo a contribuir que a mesma desenvolva as características à ela associada (Brophy, 1983; Hamermesh \& Parker, 2005).

Segundo Caetano (2006), formar impressões significa organizar uma informação sobre uma pessoa de modo a permitir uma integração destes dados em uma categoria significativa para nós. Esta categorização pode ocorrer tanto por características afetivas e cognitivas do indivíduo que analisa alguém (Asch, 1946) quanto pelas características físicas e comportamentais da pessoa-alvo, que contribuem na construção de uma determinada impressão, ou de forma mista (Zebrowitz, 1990).

O julgamento baseado em atratividade física proveniente das informações que as pessoas possuem sobre o indivíduo se verifica em estudo realizado por Lewandowski, Aron e Gee (2007), que buscaram verificar a influência de informações de personalidade em julgamentos sobre atratividade física. Os resultados indicaram modificações nos julgamentos após a inserção de dados sobre personalidade, sendo que características de personalidade mais positivas levavam em consideração os critérios de atratividade física. Posteriormente, o estudo de Lorenzo, Biesanz e Human (2010) sobre formação de impressões de traços de personalidade de pessoas fisicamente atraentes também constatou que indivíduos atraentes fisicamente eram percebidos de forma mais positiva e com maior precisão do que os indivíduos considerados menos atraentes fisicamente. Esta precisão provém do fato de que as pessoas prestam mais atenção em pessoas bonitas, embora esta precisão seja subjetiva.

Nesta perspectiva, a indústria publicitária e cosmética, visando sustentar a associação entre beleza e felicidade, apresenta padrões de beleza a serem seguidos: a imagem de modelos. Tais indivíduos são apresentados como ícones estéticos, bem como a forma mais segura de se alcançar o sucesso e a felicidade, mediante a imagem da perfeição física, associada à juventude e saúde (Gross, 1996; Wolf, 1992). Logo, as pessoas passam a reportar-se a modelos como representantes de uma "estética da perfeição" (Vilhena, Medeiros \& Novaes, 2005).

Contudo, a beleza nem sempre traz benefícios. Embora pessoas belas sejam mais populares como possíveis parceiros afetivos, a beleza física pode apresentar aspectos negativos em relações de trabalho, de amizade e até mesmo em relacionamentos amorosos.

De acordo com Etcoff (1999) e Krebs e Adinolfi (1975), mulheres bonitas têm problemas com relação à amizade com outras mulheres, sendo menos queridas pelas outras. Tal situação ocorre pelo fato de que, quando em contato com alguém muito mais belo, algumas pessoas podem sentir-se desconfortáveis e ameaçadas. No campo de relacionamentos amorosos, pessoas bonitas podem apresentar dificuldade em estabelecer relacionamentos amorosos, pois consideram que seus parceiros ou parceiras estão no relacionamento apenas pelo critério estético, ou pelo fato de perceberem que as pessoas não se aproximam por medo de rejeição (Schlösser, 2013). 
A isso se intitula "efeito de contraste" (Kenrick \& Gutierres, 1980), ou seja, pessoas sentem-se mais bonitas quando rodeadas de pessoas menos bonitas ou no mesmo nível, e feias quando em contato com pessoas reconhecidas como mais belas. Tais comparações sociais não só acontecem quando, de maneira deliberada, aprovamos ou não as pessoas que passam do nosso lado, mas também automaticamente.

Embora a literatura aponte que indivíduos fisicamente atraentes sejam tratados preferencialmente e vistos mais positivamente (Etcoff, 1999; Cunningham, 1986; Dion, Bersheis \& Walster, 1972), a beleza física voltada às relações amorosas também pode trazer desvantagens. O medo e a insegurança frente a alguém com muitas qualidades estão sempre presentes, tendo em vista que mulheres e homens considerados bonitos são mais populares com o sexo oposto, tendo maior oportunidade de se relacionar amorosamente e sexualmente com novos parceiros (Tanke, 1982; Krebs \& Adinolfi, 1975), o que pode justificar estes sentimentos negativos.

Além disso, considera-se socialmente inadequado iniciar relacionamentos amorosos tendo como base principal apenas a beleza física, devendo-se enfatizar outros atributos socialmente mais relevantes, como inteligência, senso de humor ou a "beleza interior" (Schlösser, 2013).

Com efeito, tendo em vista que a beleza se constitui como um fenômeno dotado de significados, impressões e valores, que perpassam desde o nível individual ao social, ela e sua influência nas relações amorosas serão compreendidas à luz da teoria das representações sociais (TRS), considerando sua capacidade de integrar as dimensões individuais àquelas que são socialmente partilhadas, influenciando o modo de compreender e se relacionar com a realidade (Jodelet, 1994). Moscovici (1978) define as representações sociais como sendo um conjunto de afirmações, conceitos e explicações que formam uma teoria do senso comum, inserida no universo das opiniões e conceitos dados aos fenômenos do cotidiano.

Jodelet (2001) complementou tal construto ao enfatizar que as representações sociais (RS) são uma forma de conhecimento elaborado e partilhado socialmente, com um objetivo prático, convergindo para a construção de uma realidade comum a um grupo social sobre um determinado objeto. A partir destas representações, pode-se acessar a maneira como indivíduos compreendem determinado fenômeno e quais atitudes tomam frente ao mesmo, atuando como um guia para a ação (Abric, 1998). Estudos voltados às representações sociais do corpo demonstram o papel central que este objeto possui nas relações sociais, associando-se à influência nas impressões e relações sociais, bem como na sedução (Camargo, Goetz \& Barbará, 2005; Camargo, Goetz, Barbará \& Justo, 2007; Camargo, Justo \& Aguiar, 2008; Jodelet, 1994; Justo, Camargo, Moreira \& Goetz, 2009).

Além disso, elegeram-se os fenômenos da beleza física e relacionamentos amorosos como principais objetos nesta investigação científica por sua intrínseca relação com o bemestar subjetivo, uma vez que os relacionamentos interpessoais compõem o quadro das principais causas de felicidade, junto ao trabalho e ao lazer (Argyle, 2001; Souza, 2006). Tendo em vista que a aparência é a parte mais pública da pessoa, os padrões de beleza adentram na temática como sendo as proporções e aspectos físicos considerados atrativos sexualmente, atuando diretamente nas representações sociais da beleza, uma vez que se difundem modos de comportamento e pensamento em relação aos padrões corporais 
(Camargo, Goetz, Bousfield \& Justo, 2011), interferindo tanto nas atitudes frente à beleza quanto na forma como as pessoas relacionam-se em suas interações sociais.

Embora o cotidiano esteja repleto de valores, crenças, saberes e atitudes, nem todos podem ser abertamente expressados, uma vez que, em alguns fenômenos da realidade, normas sociais entram em conflito com cognições e crenças individuais (Guimelli \& Deschamps, 2000; Menin, 2006). Visando lidar com esta limitação, que pode invalidar pesquisas no campo da representação social, apresenta-se o conceito de zona muda. Conceitua-se como zona muda das representações sociais espaços de representações que, embora façam parte do cotidiano de determinado grupo e sejam partilhados pelos seus integrantes, não são revelados em seus discursos, uma vez que apresentam aspectos contranormativos, não sendo adequados em relações às normas sociais (Abric, 2003b, 2005; Menin, 2006). De acordo com Abric (2003b), para determinados objetos sociais, em contextos específicos, existe uma zona muda de representação social, formada por elementos que não são verbalizáveis pelos indivíduos pelos métodos clássicos de coleta de dados.

Segundo Guimelli e Deschamp (2000), a zona muda é formada por elementos "contranormativos" das representações sociais, por meio de crenças e cognições não expressas por conflitar com os valores e condutas morais de determinados grupos. De acordo com a teoria do núcleo central, proposta por Abric $(1976,2003 a)$ uma representação é formada por elementos que diferem entre elementos centrais - funcionais ou normativos e periféricos. No caso de uma zona muda, esta pode compor o quadro de elementos do núcleo central de uma representação, porém fica oculta ou é mascarada, devido a seu caráter contranormativo, não podendo ser expressável. Além disso, possuem caráter normativo, uma vez que apresenta normas e valores considerados negativos para seu grupo social.

Alguns métodos foram desenvolvidos visando revelar os elementos da zona muda de uma representação, a partir da diminuição da pressão normativa do indivíduo que representa um grupo. O primeiro chama-se "técnica de substituição", no qual o indivíduo poderá apresentar suas representações sobre um dado fenômeno, atribuindo-a a outras pessoas, e não a si mesmo. Solicita-se ao indivíduo que relate sua opinião pessoal sobre uma temática, e posteriormente responda como outra pessoa responderia sobre o mesmo assunto (Menin, 2006). A segunda técnica intitula-se "técnica de descontextualização normativa", no qual se busca alocar o indivíduo numa situação mais distante de seu grupo de referência, podendo expressar seus pensamentos, minimizando o risco de julgamento por parte de possíveis pares.

Nas relações sociais, verbalizar a priorização da beleza física como condição essencial para iniciar um relacionamento amoroso tende a ser considerado como algo negativo, tornando-se assim um elemento contranormativo. O estudo parte da seguinte hipótese: embora a beleza física possua um caráter contranormativo em contextos de estabelecimento de relacionamentos amorosos, o sexo masculino e o grupo de modelos tende a não se influenciar por este fenômeno, explicitando sua importância, enquanto o sexo feminino e o grupo de não modelos serão influenciados pelo caráter contranormativo, revelando-a apenas por meio de substituição. Para tanto, a presente pesquisa busca investigar a existência de uma zona muda das RS da beleza física em contexto de estabelecimento de relacionamentos amorosos, bem como identificar diferentes elementos 
representacionais da beleza física em contexto de estabelecimento de relacionamentos amorosos, de acordo com o sexo dos participantes.

\section{Método}

Trata-se de um estudo de natureza descritiva e comparativa (Gil, 1995). Também se caracteriza pelas seguintes especificidades: transversal (Richardson, 2009) - considerando que o mesmo ocorreu num determinado tempo cronológico, descrevendo especificidades dos participantes num determinado momento de sua trajetória de vida (Richardson, 2009) e de amostragem intencional, uma vez que foram escolhidos de maneira intencional grupos específicos que compuseram a amostra (Marconi \& Lakatos, 2007).

\section{Participantes}

Participaram 120 indivíduos, distribuídos de modo equivalente entre homens e mulheres, sendo 60 deles fazendo parte do grupo que atuam como modelos fotográficos profissionais ( 30 do sexo masculino e 30 do sexo feminino), e outros 60 com acadêmicos que cursam algum curso de Ciências Exatas ou Tecnológicas ( 30 do sexo masculino e 30 do sexo feminino), fazendo parte do grupo de não modelos. Na escolha dos grupos atentou-se à relação que os mesmos tinham com o fenômeno da beleza física, podendo apresentar diferentes percepções frente a este constructo. No caso de modelos, foram escolhidos mediante sua relação direta com o fenômeno da beleza física, sendo esta a sua profissão. 0 grupo de não modelos foi escolhido com acadêmicos de cursos que, profissionalmente, estivessem mais distantes do fenômeno da beleza física, embora não fosse possível descartar a importância que a beleza tenha em suas relações interpessoais. As variáveis sexo e grupo foram controladas, para verificação de possíveis diferenciações. A média de idade do sexo masculino foi de $24,37(D P=4,72)$, e do sexo feminino $22,7(D P=4,17)$. Por sua vez, a média de idade do grupo de modelos foi $23,53(D P=4,49)$, enquanto do grupo de não modelos foi de $22,07(D P=3,94)$.

\section{Procedimento}

Foi realizado um contato inicial - por meio de e-mail e contato pessoal - com agências de modelos e as coordenações dos cursos acadêmicos elencados, visando explicar os objetivos da pesquisa e obter a liberação para ter acesso aos participantes. Posteriormente, antes da coleta dos dados, foi realizado um estudo piloto com os instrumentos online, com 20 voluntários, objetivando verificar se o questionário respondia aos objetivos da pesquisa, aprimorando-o a uma versão definitiva.

As agências de modelos que se dispuseram contribuir na pesquisa passaram o endereço eletrônico de seus respectivos profissionais, para que o pesquisador pudesse entrar em contato para fazer o convite para participar da pesquisa e explicar seus objetivos. Com relação ao grupo de acadêmicos, após o coordenador dos cursos permitir o acesso às turmas, o pesquisador fez o convite aos participantes em sala de aula, explicando os objetivos da pesquisa e entregando um cartão no qual havia o endereço online para acessar a pesquisa. Os participantes tiveram acesso a algumas informações sobre a pesquisa e a garantia de sigilo, mediante o Termo de Consentimento Livre e Esclarecido (que compôs o questionário), podendo parar de responder a qualquer momento. Os nomes dos autores 
foram fornecidos ao final da pesquisa, para possível contato, visando evitar que este dado se torne uma variável interveniente.

\section{Instrumento}

Foi utilizado um questionário online autoaplicável, com respostas abertas e fechadas, visando captar uma possível zona muda da beleza física em contextos de estabelecimento de relacionamentos amorosos. Foi composto da seguinte forma:

a) descrição de um personagem fictício, contendo informações sobre sua personalidade, aspectos físicos e como se relaciona em relacionamentos amorosos: "A pessoa de quem estamos falando possui 23 anos de idade. Esta pessoa é formada num curso superior e atua como modelo profissional. Ganha um bom salário, o que a torna uma pessoa independente financeiramente, além de ser reconhecida em sua profissão. É uma pessoa bastante inteligente, compromissada, companheira e atenciosa. Gosta de ir para festas com amigos, mas também gosta de ficar em casa. É uma pessoa comunicativa, honesta, segura e com senso de humor. Os amigos dizem que é uma pessoa confiável, tolerante, que se dedica aos amigos e evita conflitos. De modo geral, é uma pessoa considerada muito atraente, muito popular e sensual, o que chama atenção em que estiver por sua beleza. Tem um corpo bem definido, e percebe-se que é uma pessoa bastante disputada. É heterossexual, pois se relaciona apenas com pessoas do sexo oposto. Em termos sexuais, gosta muito de sexo e o acha importante em relações amorosas. Contudo, não faz sexo com muitas pessoas diferentes, pois acha importante se preservar. Prefere relacionamentos sérios e duradouros, com intimidade, paixão e compromisso. É fiel, e mesmo chamando atenção, jamais trairia a pessoa com quem se relaciona amorosamente. Costuma ser uma pessoa comprometida, atenciosa e carinhosa nos relacionamentos amorosos".

b) definição do sexo do personagem: “De qual sexo você imagina ser essa pessoa?"

c) teste de evocação: "Indique as cinco características que você lembra da pessoa citada".

d) técnica de substituição para captar elementos da zona muda (conforme já descrita na introdução): "Cite cinco características que você acha que as pessoas privilegiariam ao querer namorar com a pessoa descrita". Ressalta-se que nesta questão, não houve equivalência com o teste de evocação, tendo em vista a variação das perguntas com enfoques diferentes, influenciando assim nas respostas obtidas.

e) questões sócio-demográficas (sexo, idade e atividade profissional).

\section{Análise de dados}

Realizou-se análise estatística descritiva (média, desvio-padrão, distribuição de frequências) dos participantes e seus respectivos grupos e evocações, e estatística inferencial (teste do Qui-quadrado), visando identificar as relações entre os elementos provenientes dos testes de evocação e as variáveis sexo e grupo. Os dados foram digitados em uma planilha e analisados com o auxílio do programa estatístico Statistical Package for Social Sciences (SPSS- versão 17.0).

A análise dos dados obtidos pelos testes de evocação livre buscou comparar os participantes em função de sexo e grupo, verificando se existem diferenças significativas em suas evocações, a partir de suas frequências. Para auxiliar nesta contagem foi utilizado o 
programa informático denominado Evocation 2005 (Vergès, Scano \& Junique, 2002), o qual permite também a realização de uma análise comparativa entre sub-grupos.

\section{Resultados}

\section{Resultados provenientes do sexo dos participantes}

Como resultado geral, $75 \%$ dos participantes apontaram que a descrição retratava uma pessoa do sexo feminino. Este valor ocorreu também independente do sexo do participante, uma vez que $75 \%$ dos homens e das mulheres também apontaram que o personagem era do sexo feminino.

Ao se verificar as evocações e frequências, algumas palavras foram evocadas apenas para indivíduos que consideravam o personagem fictício um homem. Nas evocações de mulheres, verificaram-se as expressões "oportunista", "preguiçosa", "poder", "elegante" e "mente aberta". Já os homens evocaram as palavras "trabalhador", "responsável" e "séria". No caso de evocações específicas para o sexo feminino, verificaram-se evocações diferenciadas apenas do sexo masculino, como "sensual", "corpo definido" e "se preserva".

Embora não tenham apresentado diferenças estatisticamente significativas, alguns elementos apresentam dados relevantes. O elemento "companheirismo" foi citado oito vezes no total pelo sexo feminino conforme se verifica na Tabela 1 , sendo seis vezes citadas ao se associar o personagem fictício ao sexo masculino. Com relação aos homens, das dezenove vezes que foi citado, em apenas três vezes a palavra foi evocada associando o personagem fictício ao sexo masculino. O mesmo ocorreu com o elemento "gosta de sexo", citado na totalidade oito vezes pelo sexo feminino e associado a um personagem do sexo masculino seis vezes. Para os homens, das vinte e nove citações do elemento "gosta de sexo", apenas em um caso este elemento foi citado associando as características do personagem fictício ao sexo masculino. Com relação aos elementos "estabilidade financeira" e "bem sucedida", ambos foram citados doze vezes pelo sexo feminino, e em todos eles a metade deste valor se associou a um personagem do sexo masculino. Para o sexo masculino, das oito citações do elemento "bem sucedido", cinco delas foram citadas associando o personagem ao sexo masculino. Já com o elemento "estabilidade financeira", das doze vezes que foi evocado, apenas três se associou a um personagem do sexo masculino. Das seis vezes que o elemento "senso de humor" foi citado, em apenas dois casos estava associado ao sexo masculino.

Na condição normal, houve 635 evocações, com 59 palavras diferentes. Para o sexo masculino, as 5 evocações com maior frequência foram: 1. Beleza física; 2. Fidelidade; 3. Inteligência; 4. Gosta de sexo; 5. Amigável/Companheirismo. De acordo com o sexo feminino, as 5 palavras com maior frequência de evocação foram: 1. Fidelidade; 2. Beleza física; 3.Inteligência; 4. Senso de humor; 5. Estabilidade financeira/bem sucedida.

Com relação ao teste de substituição, houve 578 evocações, com 45 palavras diferentes. Para o sexo masculino, as 5 evocações com maior frequência foram: 1 . Beleza física; 2. Fidelidade; 3. Gosta de sexo; 4. Inteligência; 5 .Amigável. Já para o sexo feminino, as 5 evocações com maior frequência foram: 1. Beleza física; 2 . Fidelidade; 3 . Inteligência; 4. Companheirismo; 5 . Senso de humor. A Tabela 1 apresenta as evocações e frequências, com a lista de palavras evocadas pelos sexos. $O$ critério utilizado para as palavras adentrarem na tabela foi o critério de frequência $\geq 12$ no total de evocações. 
Tabela 1- Evocações e frequências, de acordo com o sexo dos participantes

\begin{tabular}{|c|c|c|c|c|c|c|c|c|c|c|c|}
\hline \multirow[b]{2}{*}{ Palavras } & \multicolumn{3}{|c|}{ Normal } & \multicolumn{3}{|c|}{ Substituição } & \multicolumn{5}{|c|}{ Qui-quadrado } \\
\hline & $\begin{array}{c}\text { Homens } \\
1\end{array}$ & $\begin{array}{c}\text { Mulheres } \\
2\end{array}$ & $\begin{array}{c}\text { Total } \\
3\end{array}$ & $\begin{array}{c}\text { Homens } \\
4\end{array}$ & $\begin{array}{c}\text { Mulheres } \\
5\end{array}$ & $\begin{array}{c}\text { Total } \\
6\end{array}$ & $1-2$ & $4-5$ & $3-6$ & $1-4$ & $2-5$ \\
\hline Beleza física & 54 & 32 & 86 & 56 & 55 & 111 & $5.62 *$ & .01 & 3.17 & .03 & $6.08^{*}$ \\
\hline Fidelidade & 37 & 35 & 72 & 44 & 34 & 68 & .056 & 1.2 & .11 & .60 & .01 \\
\hline Inteligência & 32 & 21 & 53 & 30 & 24 & 54 & 2.28 & .67 & .01 & .06 & .20 \\
\hline Gosta de sexo & 29 & 08 & 37 & 35 & 10 & 45 & $11.9 * *$ & $13.8 * * *$ & .78 & .56 & .22 \\
\hline Amigável & 19 & 08 & 27 & 18 & 11 & 29 & $4.48^{*}$ & 1.69 & .071 & .028 & .47 \\
\hline $\begin{array}{l}\text { Companheiris } \\
\text { mo }\end{array}$ & 19 & 08 & 27 & 10 & 19 & 29 & $4.48 *$ & 2.79 & .071 & 2.79 & $4.48 *$ \\
\hline $\begin{array}{l}\text { Estabilidade } \\
\text { financeira }\end{array}$ & 12 & 12 & 24 & 15 & 14 & 29 & .14 & .33 & .47 & .33 & .33 \\
\hline Bem sucedida & 08 & 12 & 20 & 01 & 02 & 03 & .80 & .33 & $12.5^{* * *}$ & $5.44 *$ & $7.14^{* *}$ \\
\hline $\begin{array}{l}\text { Senso de } \\
\text { humor }\end{array}$ & 08 & 16 & 24 & 13 & 18 & 31 & 2.66 & .80 & .89 & 1.19 & .11 \\
\hline Honestidade & 06 & 10 & 16 & 02 & 09 & 11 & 1.0 & $4.45^{*}$ & .92 & 2.0 & .05 \\
\hline
\end{tabular}

$*_{p}<.05 ; * * p .01, * * * p<.001$

A evocação "beleza física" apresentou diferença estatisticamente significativa em relação aos sexos na condição normal $\left[x^{2}=(1, N=120)=5.00, p<.05\right]$, com maior frequência de evocações de homens do que de mulheres, bem como entre as mulheres na condição normal e de substituição $\left[x^{2}=(1, N=120)=7.35, p<.05\right]$, com aumento da frequência da evocação na condição de substituição.

A evocação "amigável" apresentou diferença estatisticamente significativa $\left[x^{2}=(1\right.$, $\mathrm{N}=120)=4.48, p<.05)]$ com maior frequência de evocações do sexo masculino do que do sexo feminino na condição normal. O mesmo ocorreu com a evocação "gosta de sexo", com maior número de evocações do sexo masculino do que do sexo feminino na condição normal, conforme Tabela 1, apresentando diferença estatisticamente significativa $\left[x^{2}=(1\right.$, $\mathrm{N}=120$ ) $=11.90, p<.01$ ]. Esta evocação também apresentou diferença estatisticamente significativa entre homens e mulheres na condição de substituição, com predominância do sexo masculino em relação ao sexo feminino $\left[x^{2}=(1, N=120)=14.10, p<.001\right]$.

A evocação "companheirismo" apresentou diferença estatisticamente significativa entre o sexo feminino na condição normal e de substituição $\left[x^{2}=(1, N=120)=4.48, p<.05\right]$, com aumento da frequência na evocação na condição de substituição e entre as condições 1-2. A evocação "bem sucedida" também apresentou diferença estatisticamente significativa entre o sexo masculino na condição normal e de substituição, com maior frequência na condição normal $\left[x^{2}=(1, N=120)=5.44, p<.05\right]$, e entre o sexo feminino na condição normal e de substituição, também com maior frequência na condição normal $\left[x^{2}=\right.$ $(1, N=120)=9.30, p<.01]$. Esta evocação também apresentou diferença estatisticamente significativa no total de frequências na condição normal e de substituição, com predomínio de evocações na condição normal $\left[x^{2}=(1, N=120)=14.70, p<.001\right]$. 
Observa-se que as evocações com diferença estatisticamente significativas entre os sexos trazem elementos que corroboram a noção de que os homens levam mais em consideração a beleza física e o sexo do que as mulheres. Com relação à beleza física, os resultados apresentaram diferença estatisticamente significativa entre os totais desta evocação na condição normal e de substituição, manifestando assim um possível valor social dado a este fenômeno que em condições normais não se manifestaria, ou seja, uma zona muda. Verificou-se que as mulheres em condição de substituição consideram mais importante a beleza física como condição importante para relações amorosas do que na condição normal, sugerindo desta forma um possível caráter contranormativo que emergiu na situação de substituição. Ao contrário, para o sexo masculino, tanto na condição normal quanto de substituição, a beleza física apresenta-se como condição importante, sem necessitar esconder suas crenças sobre ela, mas explicitando-a.

Com relação à evocação "gosta de sexo", houve diferença estatisticamente significativa entre o sexo masculino e feminino, tanto na condição normal quanto na condição de substituição, com predomínio dos homens na frequência das evocações. Este dado sugere que os homens tanto consideram gostar de sexo importante no estabelecimento de relacionamentos amorosos, quanto acham que as outras pessoas consideram este atributo importante no estabelecimento de uma relação amorosa.

Outros elementos com diferença estatisticamente significativa trazem elementos que também apresentam características consideradas importantes para a gênese de relacionamentos amorosos. O elemento "estabilidade financeira" apresentou diferença estatisticamente significativa no total de frequências, com predomínio na situação de substituição, sugerindo que os participantes acreditam que as pessoas valorizam a estabilidade financeira para iniciar relacionamentos amorosos. Assim como a beleza física, a estabilidade financeira também se apresenta socialmente como um elemento contranormativo, uma vez que se considera imoral iniciar uma relação amorosa tendo por critério a questão financeira de um dos parceiros. Este fato por ter sido um dos motivadores para a manifestação maior desta evocação na situação de evocação, haja vista sua dimensão contranormativa.

Para os homens, na condição normal, ser "amigável" e "bem sucedida" se apresenta um elemento importante, enquanto para as mulheres, na condição normal, ser "bem sucedida" também apresenta maior importância. Na condição de substituição, o "companheirismo" se manifestou entre o sexo feminino, podendo significar que as mulheres percebem este elemento como importante para outras pessoas, de modo geral.

\section{Resultados provenientes dos grupos profissionais}

Com relação aos grupos profissionais, tanto modelos quanto não modelos predominantemente apontaram que a pessoa fictícia era mulher, respectivamente $78.3 \%$ e 71.7\%. As 5 evocações com maior frequência foram: 1. Beleza física; 2. Fidelidade; 3. Gosta de sexo/inteligência; 4. Companheirismo; 5 . Amigável. Por sua vez, as cinco evocações com alta frequência do grupo de não modelos foram: 1. Beleza física; 2. Fidelidade; 3. Inteligência; 4. Estabilidade financeira; 5. Senso de humor. A Tabela 2 apresenta os resultados das evocações em condição normal e de substituição, de acordo com os grupos profissionais. 
Tabela 2- Evocações e frequências, de acordo com a profissão dos participantes

\begin{tabular}{|c|c|c|c|c|c|c|c|c|c|c|c|}
\hline & \multicolumn{3}{|c|}{ Normal } & \multicolumn{3}{|c|}{ Substituição } & \multicolumn{5}{|c|}{ Qui-quadrado } \\
\hline alavras & $\begin{array}{c}\text { Modelos } \\
1\end{array}$ & $\begin{array}{c}\text { Não } \\
\text { Modelos } \\
2\end{array}$ & $\begin{array}{c}\text { Total } \\
3\end{array}$ & $\begin{array}{c}\text { Modelos } \\
4\end{array}$ & $\begin{array}{c}\text { Não } \\
\text { Modelos } \\
5\end{array}$ & $\begin{array}{c}\text { Total } \\
6\end{array}$ & $1-2$ & $4-5$ & $3-6$ & $1-4$ & $2-5$ \\
\hline & 48 & 38 & 86 & 58 & 53 & 111 & 1.16 & .22 & 3.17 & .94 & 2.47 \\
\hline Fidelidade & 38 & 34 & 72 & 37 & 31 & 68 & .22 & .53 & .11 & .013 & .14 \\
\hline Inteligência & 24 & 29 & 53 & 23 & 31 & 54 & .47 & 1.18 & .01 & .021 & .067 \\
\hline Gosta de sexo & 24 & 13 & 37 & 17 & 28 & 45 & 3.27 & 2.69 & .78 & 1.19 & .67 \\
\hline Amigável & 18 & 09 & 27 & 19 & 10 & 29 & 3.0 & 2.69 & .07 & .02 & .05 \\
\hline Companheirismo & 23 & 04 & 27 & 08 & 21 & 29 & $13.4 * * *$ & $5.83^{*}$ & .07 & $7.26^{*}$ & $11.5^{* *}$ \\
\hline $\begin{array}{l}\text { Estabilidade } \\
\text { financeira }\end{array}$ & 04 & 20 & 24 & 19 & 10 & 29 & $10.6^{* *}$ & 2.79 & .47 & $9.7 * *$ & 3.33 \\
\hline Bem sucedida & 09 & 11 & 20 & 01 & 02 & 03 & .20 & .33 & $12.5^{* * *}$ & $6.44 * *$ & $6.23 * *$ \\
\hline Senso de humor & 07 & 17 & 24 & 13 & 18 & 31 & $4.17^{*}$ & .80 & $12.5 * * *$ & 1.80 & .03 \\
\hline Honestidade & 03 & 13 & 16 & 05 & 06 & 11 & $6.25^{*}$ & .09 & .92 & .50 & 2.58 \\
\hline
\end{tabular}

${ }^{*} p<.05 ; * * p .01, * * * p<.001$

O elemento "companheirismo" apresentou diferença estatisticamente significativa em quatro associações: entre modelos e não modelos na condição normal, com maior frequência de evocação do grupo de modelos $\left[x^{2}=(1, N=120)=13.40, p<.001\right]$; entre modelos na condição normal e de substituição, com maior frequência de evocação do grupo de modelos na condição normal $\left[x^{2}=(1, N=120)=7.26, p<.05\right]$; entre modelos e não modelos na condição de substituição, com maior frequência de evocação do grupo de modelos na condição de substituição $\left[x^{2}=(1, N=120)=5.83, p<.05\right]$; e entre não modelos, na condição normal e de substituição, com freqüência maior do grupo de não modelos na condição de substituição $\left[x^{2}=(1, N=120)=11.50, p<.01\right]$. Estes resultados apontam o "companheirismo" como um elemento importante para o grupo de modelos, explicitando sua importância em contextos normativos. Para o grupo de não modelos, foi mais evidente na condição de substituição, indicando que podem considerar que as outras pessoas considerem este elemento um fator importante.

A evocação "estabilidade financeira" apresentou diferença estatisticamente significativa em 3 associações: entre modelos e não modelos na condição normal, com maior frequência de evocação do grupo de não modelos $\left[x^{2}=(1, N=120)=8.07, p<.01\right]$; entre modelos na condição normal e de substituição, com maior frequência de evocação de modelos na condição de substituição $\left[x^{2}=(1, N=120)=13.7, p<.001\right]$. Os dados apontam, assim como em relação ao sexo dos participantes, que o elemento "estabilidade financeira" manifestou-se com maior ênfase na condição de substituição, devido ao seu caráter contranormativo.

O elemento "bem sucedida" apresentou diferença estatisticamente significativa em 3 associações: entre modelos na condição normal e de substituição, com maior frequência de evocação na condição normal $\left[x^{2}=(1, \mathrm{~N}=120)=6.44, \mathrm{p}<.01\right]$; entre não modelos na condição normal e de substituição $\left[x^{2}=(1, N=120)=6.23, p<.01\right]$ com maior frequência de evocação na condição normal; e entre o total das frequências deste elemento na condição normal e de 
substituição, com maior frequência de evocação na condição normal $\left[x^{2}=(1, N=120)=12.5\right.$, $p<.001]$.

Os elementos "senso de humor" e "honestidade" também apresentaram diferença estatisticamente significativa. Enquanto a "honestidade" apresenta diferença entre o grupo de modelos e não modelos na condição normal, com maior frequência de evocação do grupo de não modelos $\left[x^{2}=(1, N=120)=6.25, p<.05\right]$; a evocação "senso de humor" apresenta diferença em 2 associações: entre modelos e não modelos na condição normal, com maior frequência de evocação do grupo de não modelos $\left[x^{2}=(1, N=120)=4.17, p<.05\right]$, e entre o total desta evocação nas duas condições, com frequência maior na condição de substituição $\left[x^{2}=(1, N=120)=12.5, p<.001\right]$.

Para ambos os grupos, observa-se que as evocações com diferença estatisticamente significativa levam em consideração características comportamentais do indivíduo, em detrimento de aspectos mais físicos, como o sexo e a beleza física. Ao levar em consideração as evocações com maior frequência entre os grupos profissionais, ambos evocaram elementos similares com maior quantidade, como beleza física, fidelidade e inteligência. Embora estes dados possam indicar que tais atributos sejam os mais significados na gênese de relacionamentos amorosos, é necessário cautela, devido à ausência de similaridade nas questões de evocação e substituição.

\section{Discussão}

Verifica-se no fenômeno da beleza física a relação entre RS e normas sociais, uma vez que a beleza apresenta, nos discursos sociais, aspectos normativos e contranormativos que a ela são associados nas relações interpessoais. A realização deste estudo enfocando a zona muda ocorreu a partir do questionamento de Abric (2003b): "as pessoas que interrogamos nos dizem mesmo o que pensam?" (p. 61). Nos discursos sociais, quando se associa a beleza física a relacionamentos amorosos e à amizade, observa-se que este objeto social tende a ser minimizado, sendo que quem o considera importante nestes relacionamentos passa a ser visto de modo negativo. Isso não foi verificado neste estudo, uma vez que os participantes de ambos os sexos e dos grupos profissionais apresentaram a beleza física como um elemento importante, seja no teste de evocação ou na técnica de substituição. Para os homens, a beleza foi considerada importante em todos os casos, enquanto para as mulheres foi minimizado no teste de evocação. Porém, deve-se levar em consideração o fato de que o teste de evocação pediu para que fossem evocadas as cinco palavras que recordavam do personagem, e na técnica de substituição as características que outros consideravam importante para iniciar um relacionamento amoroso. Com esta diferenciação na descrição, os participantes podem não ter associado o teste de evocação a apresentarem características que consideram importantes para si no contexto de relacionamento amoroso.

Não obstante, levando em consideração a frequência de evocações, a hipótese do estudo foi sustentada, uma vez que os homens e o grupo de modelos, tanto na técnica de evocação quanto na técnica de substituição, apontaram a beleza física como principal atributo na gênese de relacionamentos amorosos, com pouca alteração na frequência das evocações. No caso do sexo feminino, embora o número de evocações tenha sido alta no teste de evocação, houve um aumento significativo durante a técnica de substituição, corroborando na possibilidade de uma zona muda de RS da beleza física em contextos de gênese de relações amorosas. 
Os resultados apresentaram que as cinco principais associações entre os participantes na situação de evocação e de substituição foram semelhantes, uma vez que os termos estavam presentes em sua maioria, nas duas situações. Considerando que o enfoque desta pesquisa foi o fenômeno da beleza física, esta apareceu em todas as situações, ocorrendo diferença na ordem de seu aparecimento. Tanto para o sexo masculino quanto para os grupos de modelo e não modelo, no teste de evocação e na técnica de substituição, a beleza física sempre se manteve como primeiro elemento, a partir de sua frequência. Para o sexo feminino, a beleza física ficou em primeiro lugar na situação de "substituição" e em segundo na situação de evocação, ficando em primeiro o elemento "fidelidade". Estes resultados sugerem que o efeito contranormativo do objeto "beleza física" nas evocações nas condições de evocação e de 'substituição' apresentou alterações significativas, o que demonstra que a opinião pessoal e a opinião que as participantes têm de outras pessoas diferem sobre a beleza como principal fator observado para o estabelecimento de um relacionamento amoroso.

A beleza física enquanto estímulo não verbal contribui na formação de impressões, uma vez que a percepção da aparência física leva a inferência de um conjunto de traços e atitudes de determinado indivíduo (Caetano, 2006). Concorda-se aqui com o que propõe Asch (1946) e Bruner e Tagiuri (1954) de que, com um pequeno conjunto de traços-estímulo de um indivíduo, já foi suficiente para que os participantes fizessem inferências, sendo que isso ocorre por meio das "categorias implícitas de personalidade" (Bruner \& Tagiuri, 1954), em que pessoas possuem categorias para descrever outras pessoas, e com algumas informações já são capazes de elaborar inferências à situações que estão fora de sua percepção.

Nos resultados, devido à solicitação feita pelo instrumento da pesquisa, os participantes formaram uma impressão indivíduo fictício a partir de poucos dados de atributos físicos e comportamentais. Um dos efeitos possíveis pode ser proveniente do efeito de halo, isto é, ao se criar uma impressão positiva ou negativa de alguém, a tendência é que as demais características de julgamento sejam consonantes com nossa impressão (Dion, Berscheid \& Walster, 1972). Além disso, a escolha majoritária em descrever o personagem como mulher como estar relacionado à questão de estereótipos sexuais, que associam elementos como "fidelidade" e "beleza física" ao sexo feminino. Contudo, estereótipos ligados à beleza física se desenvolvem e atuam em contextos informais, o que torna difícil delimitar sua influência ou diminuir suas conseqüências negativas (Dion, 1986).

A questão do estereótipo acerca do sexo do personagem fictício adentra também na relação entre representações sociais e a questão de gênero. Os resultados apontaram algumas características que estiveram mais associadas com estereótipos masculinos ou femininos. Associados a um personagem fictício do sexo masculino, os elementos associados de modo mais acentuado foram "gosta de sexo" e "companheirismo", e em menor grau "estabilidade financeira", "senso de humor" e "bem sucedido". Já associados a um personagem feminino, os elementos foram "beleza física", "fidelidade", "sensual", "se preserva", "honestidade", "amigável”, dentre outras. Verifica-se que estas manifestações de padrões de gênero determinam valores e modelos a serem seguidos, criando paradigmas físicos, morais e mentais (Suárez, 2000).

Desse modo, para as mulheres são atribuídas - tanto pelos homens quanto pelas mulheres - qualidades físicas (beleza e sensualidade), comportamentais (se preserva, 
fidelidade, honestidade, amigável) e cognitivas (inteligência) que enfatizam um caráter mais passivo e submisso. Aos homens, o estereótipo de gênero se manifesta através dos atributos de gostar de sexo, senso de humor, estabilidade financeira e ser bem sucedido, bem como companheirismo, podendo esta ser uma característica do homem enquanto protetor (Buss \& Barnes, 1986; Buss \& Schmitt, 1993).

Estes estereótipos também podem influenciar no tipo de amor manifestado nas relações amorosas, de acordo com a teoria dualista do amor (Berscheid \& Walster, 1969). Os autores propõem dois tipos de amor: o amor companheiro e o amor paixão. Enquanto o amor companheiro está relacionado a sentimentos de cuidado e afeto, sendo uma forma de relacionamento amoroso mais maduro, consistente e comprometido, o amor paixão volta-se aos aspectos físicos e sexuais, sendo mais voltado às emoções adjacentes à sensualidade e sexualidade (Sánchez-Aragón, 2005). Neste caso, o amor companheiro associa-se ao estereótipo feminino, com manifestações de fidelidade, honestidade e amizade. No caso dos homens, manifesta-se no tipo de amor paixão, por meio das manifestações de elementos voltados à sexualidade.

Além disso, os resultados da presente pesquisa apontam também para critérios diferentes na escolha de parceiros entre homens e mulheres. Estudos realizados (Buss \& Barnes, 1986; Kendrick, Sadalla, Groth \& Trost, 1990) apontaram que, para mulheres, critérios como amizade, inteligência, criatividade, senso de humor, estabilidade emocional, posição social e nível de escolaridade são importantes na escolha de parceiros. Para o sexo masculino, embora valorizem os critérios apontados pelas mulheres, apontam a beleza como a mais importante. Estes dados puderam ser observados dos resultados de Buss e Barnes (1986) e Kendrick e colaboradores (1990), nos quais os homens colocam a beleza física como atributo mais importante em suas evocações, enquanto as mulheres apresentam a fidelidade e outros atributos. Kendrick et al. (1990) apontam que mulheres são mais criteriosas nas escolhas de parceiros em qualquer nível de relação, enquanto os homens o são para a escolha de parceiros em relacionamentos duradouros. Ressalta-se que tais estudos enfatizam a escolha de parceiros para fins de casamento ou para relações mais duradouras.

Verifica-se com estes dados como as experiências de gênero, vividas por meio das RS como forma conhecimento concreto, influenciam nas atitudes frente às relações sociais. Além disso, também aponta como diferentes grupos apresentam diferentes visões sobre um mesmo objeto (Arruda, 2002). Esses papeis que cada grupo assume no contexto social orientam as práticas que se espera encontrar em homens e mulheres, expressando assim as diferenças sexuais enquanto convenções sociais formadas por representações sociais e culturais (Cabral \& Diaz, 1999; Carloto, 2001; Santana \& Benevento, 2013) que constroem tanto as normas sociais, como também as identidades pessoais e sociais.

Com relação aos demais elementos que também apareceram nas evocações, a "fidelidade" foi um dos elementos estáveis para os participantes, bem como a "inteligência". O elemento "gosta de sexo" se fez presente para o sexo masculino e para o grupo de modelos na situação "normal" e de "substituição". A literatura aponta que o sexo é um elemento que envolve o julgamento da qualidade dos atributos de ordem sexual, tais como prazer e desejo de envolvimento em situações sexuais (De Andrade, Garcia \& Cano, 2009). O desejo, atração e necessidade de encontrar satisfação sexual são variáveis importantes para se estabelecer um relacionamento amoroso (Sánchez, 2005). De acordo com alguns estudos (Berscheid, Dion, Walster \& Walster, 1971; Feingold, 1991; Sprecher et al., 1994), o sexo 
masculino considera mais importante os atributos físicos do sexo oposto. Contudo, ressaltase que tais diferenças minimizam à medida que se altere as questões de padrões sexuais.

O elemento "estabilidade financeira" merece destaque. Assim como a beleza física, a questão da estabilidade financeira também pode ser considerada um elemento contranormativo, uma vez que entra em conflito com os valores morais e normas sociais (Guimelli \& Deschamp, 2000). Interessar-se tanto pela posição social quanto pela questão financeira é visto de modo negativo na contemporaneidade, atrelando àqueles que a valorizam adjetivos como "interesseiros". Tanto no caso da beleza física quanto na de estabilidade econômica, outro aspecto que levaria à existência de uma zona muda seria a tentativa, por parte dos sujeitos, de gerar uma imagem positiva de si (Abric, 2005). Desta maneira, a desejabilidade social poderia ser um dos constructos para a existência de facetas mascaradas na expressão de determinadas representações sociais.

O elemento "estabilidade financeira" apresentou diferenças estatisticamente significativas para o grupo de modelos e não modelos, bem como entre o grupo de modelos, na condição "normal" e de "substituição". Ou seja, os resultados apontam que o grupo de não modelos considera um elemento importante no estabelecimento de vínculos amorosos, enquanto que o grupo de modelos considera que as outras pessoas valorizam a dimensão econômica no momento de estabelecer relacionamentos amorosos. De acordo com Menin (2006) certos elementos da representação, mesmo aqueles que podem ser centrais, podem ficar "escondidos" de forma que o que aparece são os elementos periféricos.

Deschamps e Guimelli (2004) pontuam que, quando determinados assuntos apresentam conteúdos contranormativos, responder de acordo com o que as pessoas pensam verdadeiramente pode "manchar" a imagem de quem as faz. Para Abric (2003b), existem certos objetos "sensíveis", no qual seu campo representacional possui cognições e crenças que, caso expressas, põem em xeque valores morais. No caso da técnica de substituição, Deschamps e Guimelli (2004) questionam que as representações na situação de "substituição" podem apenas revelar o que os sujeitos pensam ser as representações de outros, conhecendo, portanto, os estereótipos de um determinado grupo. Contudo, é mais provável que as respostas evidenciem o efeito da "zona muda", ou seja, os indivíduos não apenas expressam estereótipos sociais, mas valores e crenças pessoais consideradas socialmente inadequadas ou polêmicas. Ao retirar a pressão pela opinião individual, o indivíduo pode sentir-se menos inibido, permitindo-se verbalizar suas opiniões sem preocupar-se com possíveis coerções sociais.

A questão da fidelidade também apresentou importância. A identificação da fidelidade para relacionamentos amorosos permanece como um valor para a sociedade, apesar das enormes mudanças nas relações afetivo-sexuais na contemporaneidade (Goldenberg, 2006). A infidelidade é condenada socialmente em todos os tipos de relacionamentos amorosos (namoros, noivados, casamentos), além de ser considerado como uma das preocupações mais inquietantes em relações afetivo-sexuais (Gomes, Amboni \& Almeida, 2011; Pires, Abreu, Urbinati, Tilio \& Almeida, 2011). Nesses casos os indivíduos são temerosos de que seus parceiros (as) encontrem companheiros (as) mais atraentes e sejam infiéis, o que tende a gerar outras complicações no relacionamento, como o ciúme romântico, por exemplo.

Com relação ao elemento "companheirismo", o mesmo está presente no conjunto de aspectos interpessoais dos relacionamentos amorosos, juntamente com a paixão, companheirismo, intimidade, paixão, compromisso e percepção de reciprocidade afetiva 
(Rubin, 1970; Sternberg, 1989). Já o "senso de humor" também foi identificado como um elemento importante enquanto qualidade de um indivíduo, sendo que o humor no relacionamento permite torná-lo mais leve, frente às dificuldades do cotidiano.

Acerca do elemento "confiança", Lewicki, McAllister e Bies (1998), entendem-na como uma expectativa positiva pela conduta alheia, influenciando o quanto uma pessoa poderá ser aberta e íntima à outra. De acordo com Silva (2005), a melhor maneira de conhecer o outro, desenvolver intimidade e apresentar credibilidade moral é através da confiança, pois através dela diminuem-se as inseguranças e incertezas. Já a "inteligência" se caracteriza como um atrativo na seleção de parceiros, sendo assim considerada, pois o indivíduo que a possui é visto como mais capacitado para lidar com diferentes situações, podendo obter maior sucesso e conquistas profissionais (Stojanowska, 2003; Wright, 1996).

\section{Considerações finais}

Temática debatida há séculos e ainda contemporânea, o fenômeno da beleza física tem atraído cada vez mais estudos, visando compreender seus atributos e aspectos relacionais. Em se tratando de atração interpessoal, a beleza física assume status de elemento central, embora nem sempre expressado socialmente, devido a seu caráter potencialmente contranormativo (Adams, 1977; Byrne, 1971; Camargo et al., 2005; Camargo et al., 2007; Feingold, 1990; Gomes \& Caramaschi, 2007; Gomes, Gouveia, Silva Júnior, Coutinho \& Santos, 2013; Gottschall, 2008; Krebs \& Adinolfi, 1975; Langmeyer \& Shank; 1995; Lemay, Clark \& Greenberg, 2010; Murstein, 1972; Stojanowska, 2003; Tanke, 1982; Schlösser \& Camargo, 2015).

Contudo, os resultados deste estudo verificaram que, para os participantes do sexo masculino e para o grupo de modelos, a beleza física não foi percebida como algo contranormativo. Para o sexo feminino e grupo de não modelos, a beleza física também se apresenta como um elemento importante na gênese de relacionamentos amorosos, contudo apresentou um aumento significativo na condição de substituição, o que pode indicar a existência da contranormatividade da beleza neste contexto.

Os resultados obtidos permitem considerar a beleza física ainda como elemento contranormativo, mas que se manifesta em diferentes níveis de acordo com os grupos profissionais e sexo. Fazem-se necessários estudos com maior amplitude, através de populações e idades diferenciadas, bem como metodologias diferenciadas, gerando assim resultados mais consistentes. Uma das limitações deste estudo reside na não equivalência entre o teste de evocação e a técnica de substituição, devido à variação das perguntas com enfoques diferentes. Sugere-se para estudos futuros o desenvolvimento das duas questões de forma homogênea, captando de forma mais assertiva os resultados. Ademais, percebeuse a carência de estudos nacionais no campo da atração interpessoal, campo clássico do conhecimento da psicologia social, necessitando mais trabalhados no cenário brasileiro.

\section{Referências}

Abric, J. (1976). Jeux, Conflits et représentations sociales. Thèse de doctorat, Université de Pronvence, Aix-enProvence.

Abric, J. C. (1998). A abordagem estrutural das representações sociais. In A. S. P. Moreira \& D. C. de Oliveira (Orgs.). Estudos interdisciplinares de representações sociais (pp. 27-38). Goiânia: AB. 
Abric, J. C. (2003a). Abordagem estrutural das representações sociais: desenvolvimentos recentes. In P. H. F. Campos \& M. C. da S. Loureiro (Orgs.). Representações sociais e práticas educativas (pp. 37-57). Goiânia: UCG.

Abric, J. C. (2003b). La recherche du noyau central et de la zone muette des représentations sociales. In J. C. Abric (Org.). Méthodes d'étude des représentations sociales (pp. 59-80). Saint-Agne: ÉRÈS.

Abric, J. C. (2005). A zona muda das representações sociais. In D. C. Oliveira \& P. H. F. Campos. Representações sociais: uma teoria sem fronteiras. (pp. 23-34). Rio de Janeiro: Museu da República (Coleção Memória Social).

Adams, G. (1977). Physical attractiveness research: Toward a developmental social psychology of beauty. Human Development, 20, 217-239.

Alferes, V. R. (2006). Atracção interpessoal, sexualidade e relações íntimas. In J. Vala \& M. B. Monteiro. Psicologia social (7ạ ed., pp. 15-158): Fundação Calouste Gulbenkian, Lisboa.

Andrieu, B. (2006). Le dictionnaire du corps em sciences humaines e sociales. Paris: CNRS Editions.

Argyle, M. (2001). The psychology of happiness (2ª ed.). Hove/New York: Routledge/ Taylor \& Francis.

Arruda, A. (2002). Teoria das representações sociais e teorias de gênero.Cadernos de Pesquisa, 117, 127-147.

Asch, S. (1946). Forming impressions of personality. Journal of Abnormal and Social Psychology, 41, 258-290.

Berscheid, E., Dion, K., Walster, E., \& Walster, G. W. (1971). Physical attractiveness and dating choice: a test of the matching hypothesis. Journal of Experimental Social Psychology, 7, 173-189.

Berscheid, E., \& Walster, E. (1969). Interpersonal attraction. Reading, MA: Addison Wesley.

Biddle, J. E., \& Hamermesh, D. S. (1995). Beauty, Productivity and Discrimination: Lawyers' Looks and Lucre. NBER Working Paper, 5366, 1-44.

Brophy, J. (1983). Research on the selffulfilling prophecy and teacher expectations. Journal of Educational Psychology, 76(2), 236-247.

Bruner, J. S., \& Tagiuri , R. (1954). The perception of peaple. In G. Lindzey \& E. Aronson (Eds.). Handbook of social psychology (Vol 2.) Reading: Addison-Wesley.

Buss, D. M., \& Barnes, M. (1986). Preferences in human mate selection. Journal of Personality and Social Psychology, 50(3), 559-570.

Buss, D., \& Schmitt, D. P. (1993). Sexual strategies theory: An evolutionary perspective on human mating. Psychological Rewiew, 100, 204-232.

Byrne, D. (1971). The attraction paradigma. New York: Academic Pres.

Cabral, F., \& Diaz, M. (1999). Relações de gênero. Cadernos afetividade e sexualidade na educação: um novo olhar. Secretaria Municipal de Educação de Belo Horizonte. Fundação Odebrecht. Belo Horizonte: Gráfica Editora Rona Ltda.

Caetano, A. (2006). Formação de impressões. In J. Vala \& M. B. Monteiro. Psicologia social (7ạ ed., pp.89-124). Fundação Calouste Gulbenkian, Lisboa.

Camargo, B. V., Goetz, E. R., \& Barbará, A. (2005). Representações sociais da beleza de estudantes de moda. Textos Completos da IV Jornada Internacional e III Conferência Brasileira sobre representações sociais. João Pessoa, 3353-3362.

Camargo, B. V., Goetz, E. R., Barbará, A., \& Justo, A. M. (2007). Representações sociais da beleza de estudantes de Educação Física e de Moda. Resumos de comunicações científicas online, V Jornada Internacional e III Conferência Brasileira sobre Representações sociais. Brasília.

Camargo, B. V., Justo, A. M., \& Aguiar, A. (2008). Corpo real, corpo ideal: a autoimagem definindo práticas corporais. Trabalhos Completos do VI Congresso Iberoamericano de Psicologia, Lima.

Camargo, B. V., Goetz, E. R., Bousfield, A. B. S., \& Justo, A. M. (2011). Representações sociais do corpo: estética e saúde. Temas em Psicologia, 19(1), 257-268.

Carloto, C. M. (2001). O conceito de gênero e sua importância para a análise das relações sociais. Serviço Social em Revista, 3(2), 201-213.

Cash, T. F, Gillen B., \& Burns, D. S. (1977). Sexism and beautyism in personnel consultant decision making. Journal of Applied Psychology, 62(3), 301-310.

Copeland, J. T. (1994). Prophecies of power: motivational implications of social power for behavioral confirmation. Journal of Personality and Social Psychology, 67(2), 264-277.

Cunningham, M. R. (1986). Measuning the physical in physical attractiveness: quasi-experiments on the sociobiology of female facial beauty. Journal of Personality and Social Psychology, 50, 925-935.

De Andrade, A. L., Garcia, A., \& Cano, D. S. (2009). Preditores da satisfação global em relacionamentos românticos. Psicologia: Teoria e Prática, 11(3), 143-156.

Deschamps, J. C., \& Guimelli, C. (2004). L'organisation interne des représentations sociales de la sécurité/insécurité et hypothèse de la «zone muette». In J. L. Beauvois, R. V. Joule \& J. M. Montreil. Perspectives Cognitives et Conduites Sociales (pp. 300-323). Rennes: Press Universitaire de Rennes. 
Dion, K. K. (1986). Stereotyping based on physical attractiveness. In C. P. Herman, M. P. Zanna \& E.T. Higgins (Eds.). Physical appearance, stigma, and social behavior (pp.7-21). Hillsdale, Nova Jérsia: Lawrence Erlbaum.

Dion, K. K., Berscheid, E., \& Walster, E. (1972). What is beautiful is good. Journal of Personality and Social Psychology, 24, 285-290.

Etcoff, N. (1999). A lei do mais belo: a ciência da beleza. Objetiva: Rio de Janeiro.

Feingold, A. (1990). Gender differences in effects of psysical attractinevess on romantic attraction: acomparison across Five research paradigms. Journal of Personality and Social Psychology, 59, 981-993.

Feingold, A. (1991). Sex differences in the effects of similarity and physical attractiveness on opposite-sex attraction. Basic and Applied Social Psychology, 12, 357-367.

Gil, A. C. (1995). Métodos e técnicas de pesquisa social (4ạ ed.). São Paulo: Atlas.

Goetz, E. (2009). Representações sociais do corpo, mídia e atitudes. Tese de Doutorado, Programa de PósGraduação em Psicologia, Universidade Federal de Santa Catarina, Florianópolis, SC, Brasil.

Goldenberg, M. (2006). Infiel: notas de uma antropóloga. Rio de Janeiro: Record.

Gomes, A. L., Amboni, G., \& Almeida, T. (2011). Ciúme romântico em casais heterossexuais: relatos de pessoas casadas e unidas consensualmente. Pensando Famílias, 15(2), 31-50.

Gomes, G. R., \& Caramaschi, S. (2007). Valorização de beleza e inteligência por adolescentes de diferentes classes sociais. Psicologia em Estudo, 12(2), 295-303.

Gomes, A. I. A. S. B., Gouveia, V. V., Silva Júnior, N. A., Coutinho, M. L., \& Santos, L. C. O. (2013). Escolha do(a) parceiro(a) ideal por heterossexuais: são seus valores e traços de personalidade uma explicação? Psicologia: Reflexão e Crítica, 26(1), 29-37.

Gottschall, J. (2008). The "Beauty Myth" Is No Myth Emphasis on Male-Female Attractiveness in World Folktales. HumanNature, 19, 174-188.

Gross, M. (1996). Modelo: o mundo feio das mulheres lindas. Rio de Janeiro: Objetiva.

Guimelli, C., \& Deschamps, J. C. (2000). Effet des contextes sur la production d'associations verbales: Le cas des représentations sociales des Gitanes. Les Cahiers Internationaux de Psychologie Sociale, 47, 44-54.

Hamermersh, D. S. (2011). Beauty Pays: Why Attractive People Are More Successful. Princeton University Press. Hamermesh, D. S., \& Biddle, J. E. (1993). Beauty and Labor Market. NBER Working Paper, 4518, 1-46.

Hamermesh, D., \& Abrevaya, J. (2013). “Beauty is the promise of happiness?” European Economic Review, 64, 351-368.

Hamermesh, D. S., \& Parker, A. (2005). Beauty in the classroom: instructors' pulchritude and putative pedagogical productivity. Economics of Education Review, 24(4), 369-376.

Kanazawa, S. (2011). "Intelligence and physical attractiveness". Intelligence, 39(1), 7-14.

Kendrick, D. T., Sadalla, E. K., Groth, G., \& Trost, M. R. (1990). Evolution, traits and the stage of human: Qualifyng the parental investment model. Journal Personality and Social Psychology, 58(1), 97-116.

Langmeyer, L., \& Shank, M. (1995). Body and soul: beyond physical attractiveness implications in behavior. Advances in consumer research, 22, 746-752.

Le Pape, Y. (2006). Beauté/Laideur. In B. Andrieu (Org.). Le dictionnaire du corps en sciences humaines e socials (pp.48-49). Paris: CNRS Editions.

Lemay, E. P., Clark, M. S., \& Greenberg, A. (2010). What is beautiful is good because what is beautiful is desired: Physical attractiveness stereotyping as projection of interpersonal goals. Personality and Social Psychology Bulletin, 36, 339-353.

Lewandowski, G., Aron, A., \& Gee, J. (2007). Personality goes a long way: The malleability of opposite-sex physical attractiveness. Personal Relationships, 14(4), 571-585.

Lewicki, R. J., McAllister, D. J., \& Bies, R. J (1998). Trust and distrust: new relationships and realities. Academy of Management Review, 23(3), 438-458.

Lorenzo, G. L., Biesanz, J. C., \& Human, L. J. (2010). What Is Beautiful Is Good and More Accurately Understood: Physical Attractiveness and Accuracy in First Impressions of Personality. Psychological Science, 21(12), 1777.

Jodelet, D. (1994). Le corps, la persone et autrui. In S. Moscovici (Org.). Psychologie sociale des relations à autrui (pp. 41-68). Paris: Nathan.

Jodelet, D. (2001). Representações sociais: um domínio em expansão. In D. Jodelet (Ed.). As representações sociais (pp.17-29). Rio de Janeiro: Eduerj.

Justo, A. M., Camargo, B. V., Moreira, A. B., \& Goetz, E. R. (2009). Representações sociais sobre o corpo: uma abordagem estrutural. VI Jornada Internacional de Representações sociais, Buenos Aires.

Krebs, D., \& Adinolfi, A. A. (1975). Physical attractiveness, social relations and personality style. Journal of Personality and Social Psychology, 31, 245-253.

Marconi, M. de A., \& Lakatos, E. M. (2007). Fundamentos de metodologia científica (6a ed.). São Paulo: Atlas. 
Menin, M. S. de S. (2006). Representação social e estereótipo: A zona muda das representações sociais. Psicologia: Teoria e Pesquisa, 22(1), 43-52.

Moscovici, S. (1978). A representação social da psicanálise. Rio de Janeiro: Zahar.

Murstein, B, I. (1972). Physical attractiveness and marital choice. Journal of Personality and Social Pshychology, 22(1), 8-12.

Pires, M. R. M., Abreu, M., Urbinati, M. C., Tilio, R., \& Almeida, T. (2011). Representações dos homens heterossexuais acerca do ciúme contemporâneo. Anais do III Simpósio Brasileiro de Família e Desenvolvimento Humano: prevenção, intervenção e promoção da saúde psicológica (pp.123-124). Curitiba, PR.

Richardson, R. J. (2009). Pesquisa social: Métodos e técnicas. São Paulo: Atlas.

Rosenzweig, P. (2007). The Halo Effect...and the Eight Other Business Delusions That Deceive Managers: Free Press.

Rubin, Z. (1970). Measurement of romantic love. Journal of Personality and Social Psychology, 16, 265-273.

Sánchez-Aragón, R. (2005). Mexican love styles. In A. Garcia (Ed.). Personal relationships: International studies (pp. 64- 77). Vitória: Núcleo Interdisciplinar para o Estudo do Relacionamento Interpessoal, Universidade Federal do Espírito Santo.

Santana, V. C., \& Benevento, C. T. (2013). O conceito de gênero e suas representações sociais. EFDeportes, 17(176), s-p.

Schlösser, A., \& Camargo, B. V. (2015). Representações sociais da beleza física para modelos fotográficos e não modelos. Psico, 46(2), 278-286.

Schlösser, A., \& Camargo, B. V. (prelo). Representações sociais da beleza física e sua influência no estabelecimento de relacionamentos amorosos. Interpersona, prelo.

Schlösser, A. (2013). Representações sociais da beleza física e sua influência no estabelecimento de amizade e relacionamentos amorosos. Dissertação de Mestrado, Programa de Pós-Graduação em Psicologia, Universidade Federal de Santa Catarina, Florianópolis, SC, Brasil.

Silva, G. T. (2005). Amizade: tão perto, tão longe. In A. Garcia. Relacionamento interpessoal: olhares diversos. (pp. 41-49). Vitória: GM Gráfica e Editora Ltda.

Souza, L. K. (2006). Amizade em adultos: adaptação e validação dos questionários MCGILL e um estudo de diferença de gênero. Tese de Doutorado, Programa de Pós-Graduação em Psicologia do Desenvolvimento, Universidade Federal do Rio Grande do Sul, Porto Alegre, RS, Brasil.

Sprecher, S., Aron, A., Hatfield, E., Cortese, A., Potapova, E., \& Levitskaya, A. (1994). Love: American style, Russian style, and Japanese style. Personal Relationships, 1, 349-369.

Sternberg, R. J. (1989). El Triangulo del amor: intimidad, passión y compromisso. Barcelona: Paidós.

Stojanowska, E. (2003). Effects of beauty and style of self-presentation on women's and men's interpersonal attractiveness. StudiaPsychologiczne, 41(4), 147-167.

Suárez, M. (2000). Gênero: uma palavra para desconstruir idéias e um conceito empírico e analítico. I Encontro de Intercâmbio de Experiências do Fundo de Gênero no Brasil, Brasília: [s.n.].

Tanke, E. D. (1982). Dimensions of the physical attractiveness stereotype: a factor/analytic study. Journal of Psychology, 107, 69-75.

Vergès, P., Scano, S., \& Junique, C. (2002). Ensembles de programmes permettant l'analyse des evocations. Aix en Provence : Université Aix en Provence (Manual).

Vilhena, J. de V., Medeiros, S., \& Novaes, J. de V. (2005). A violência da imagem: estética, feminino e contemporaneidade. Revista Mal-estar e subjetividade, 5(1), 109-144.

Wright, R. (1996). O animal moral - porque somos como somos: a nova ciência da Psicologia Evolucionista. Rio de Janeiro: Campus.

Wolf, N. (1992). O mito da beleza: como as imagens de beleza são usadas contra as mulheres. Rocco: Rio de Janeiro.

Zebrowitz, L. A. (1990). Social perception. Milton Keynes: Open University Pres. 